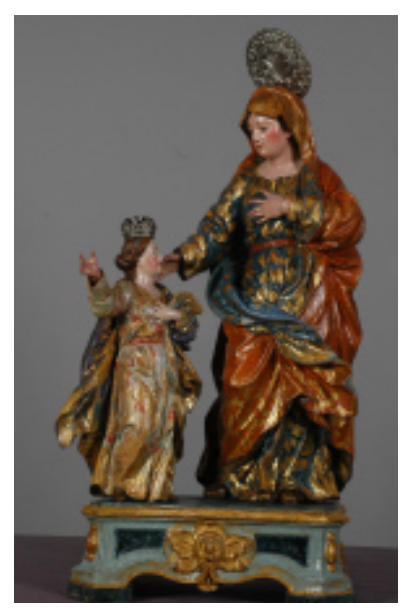

Conjunto escultórico de Santa Ana con la Virgen. Fuenteheridos, Huelva

\title{
Presentación de algunos trabajos de restauración
}

La Consejería de Cultura de la Junta de Andalucía ha restaurado en sus instalaciones del Centro de Intervención del Instituto Andaluz del Patrimonio Histórico una serie de Bienes Culturales de un importante valor histórico-artístico que durante el pasado año fueron presentados públicamente. Entre ellos destaca el pequeño conjunto escultórico de Santa Ana con la Virgen itinerantes, de la iglesia parroquial del Espíritu Santo de la localidad onubense de Fuenteheridos. Estas tallas -de origen y autoria desconocido pero de características estilísticas vinculadas a finales del siglo XVIII- se encontraban en un estado de conservación muy delicado, determinado por la falta de adhesión de la policromía al soporte, que ofrecía, especialmente en la imagen de la Virgen, gran riesgo de pérdida.

Otra de las esculturas restauradas es San Simón, pieza perteneciente a la Cartuja de Santa María de la Defensión de Jerez de la Frontera. La imagen, obra extraordinaria del escultor flamenco José de Arce, fue realizada en madera policromada en 1639 (asi se puede ver en la inscripción incisa de la peana) y representa uno de los doce apóstoles que formaban, junto con un crucificado, el repertorio escultórico del retablo mayor de la iglesia del monasterio, un retablo contratado en Jerez en 1637, siendo Alonso Cano el tracista, Francisco de Zurbarán el pintor de los cuadros que ocuparian las hornacinas y Arce el escultor encargado de la imaginería. La presentación de la talla, el pasado día 2 de diciembre, fue presidida, en una de las dependencias de la Cartuja de Jerez, por la Consejera de Cultura de la Junta de Andalucía, Rosario Torres, y el obispo de AsidoniaJerez, Juan del Río.

También la Consejera asistió, junto al alcalde de Osuna, Marcos Quijada Pérez, a la presentación, esta vez en la sede del IAPH, del lienzo El Calvario - La Expiración de Cristo de José Ribera "El Españoleto". La obra propiedad del Patronato de Arte de la Colegiata de la villa de Osuna (Sevilla) se conserva en la actualidad en la capilla de la Virgen de la Antigua, aunque su primitiva ubicación fue el retablo mayor de la iglesia, junto a otros cuatro cuadros del mismo autor. La pintura, de gran calidad técnica, está realizada al óleo sobre un gran lienzo; los personajes aparecen iluminados en sus rostros y ropajes, sobre un fondo oscuro, en el que destaca en el centro de la composición el perfecto modelado del cuerpo de Cristo, que mira al cielo con expresión serena y sin dramatismo, como si estuviese ajeno al dolor que le produce el martirio de la Crucifixión. En este óleo, Ribera logra que sobre la oscuridad triunfen los rojos, azules, verdes y amarillos, los trazos imprescindibles iluminan y hacen reflejar la luz en la obra. Los problemas que presentaba la pintura se centraban principalmente en la separación puntual entre la tela del reentelado y la original, formando bolsas de aire, y en la alteración de color provocada no sólo por la oxidación generada del barniz, sino por las reintegraciones viradas realizadas en intervenciones anteriores.

Por otro lado, el pasado año se presentó una actuación llevada a cabo por el IAPH entre los años 2000 y 2004: la restauración de los cinco lienzos originales del pintor Juan del Castillo que forman el retablo de San Juan Bautista conservado en la actualidad en la iglesia de los Sagrados Corazones de la localidad sevillana de San Juan de Aznalfarache (más información en PH 50). Los problemas que presentaban los lienzos se centraban principalmente en el soporte, con un reentelado muy inestable realizado con tela de algodón y de lino, pérdidas considerables de soporte original, y añadidos de tablas de madera bastante deterioradas, clavadas a los bastidores, que impedian ver el reverso de los cuadros y transmitían su patología al bastidor y al soporte de la tela.

Por último, el 10 de septiembre de 2004 la Consejera de Cultura y el Cardenal y Arzobispo de Sevilla, Carlos Amigo Vallejo, presentaron en la Catedral Hispalense la finalización de la intervención en el retablo de la capilla de los Evangelistas. Este retablo, realizado por Hernando de Esturmio entre 1553 y 1556, constituye la obra más conocida de la producción del pintor flamenco; está compuesto de banco, dos cuerpos con tres calles y ático, y abarca un total de diez pinturas sobre tabla. Su plazo de ejecución ha transcurrido en un periodo de treinta meses, y el objetivo de este proyecto se ha centrado en la recuperación de un retablo en madera dorada y policromada y pinturas sobre tablas debido a su avanzado estado de deterioro y a las desafortunadas intervenciones anteriores que presentaba. La intervención de esta arquitectura lignaria ha comprendido un tratamiento integral de conservación y restauración, tanto de la estructura arquitectónica, como de siete de las diez pinturas sobre tabla que lo componen (las tres tablas restantes que forman el conjunto pictórico ya fueron intervenidas con anterioridad). Con este fin se realizó el desmontaje del retablo y traslado a las dependencias del IAPH, donde se realizó para el nuevo montaje un relevo estructural en acero inoxidable, coincidiendo con el entramado de vigas que componian la estructura de sujeción y anclaje del retablo, y una intervención de las pinturas bajo unos criterios y métodos de tratamiento justificados, fundamentales para su conservación y puesta en valor, desde la perspectiva del máximo respeto a la integridad de la obra.

Gabriel Ferreras Romero

Centro de Intervención del IAPH 